\title{
DISSEMINAÇÃO DE MOLICUTES DO MILHO A LONGAS DISTÂNCIAS POR Dalbulus maidis (HEMIPTERA: CICADELLIDAE)*
}

\author{
CHARLES M. OLIVEIRA ${ }^{1 * *}$, ROSA M.S. MOLINA ${ }^{2}$, ROSENIR S. ALBRES ${ }^{2} \&$ JOÃO R.S. LOPES ${ }^{1}$
}

\author{
'Departamento de Entomologia, Fitopatologia e Zoologia Agrícola, Escola Superior de Agricultura "Luiz de Queiroz", Uni- \\ versidade de São Paulo, Cx. Postal 9, CEP 13418-900, Piracicaba, SP, Fax: (019) 433-0562, \\ e-mail: jrslopes@carpa.ciagri.usp.br; ${ }^{2}$ Departamento de Biociências, Centro Universitário de Aquidauana, \\ Universidade Federal do Mato Grosso do Sul, Cx. Postal 4, CEP 79200-000, Aquidauana, MS
}

(Aceito para publicação em 08/10/2001)

Autor para correspondência: João Roberto Spotti Lopes

OLIVEIRA, C.M., MOLINA, R.M.S., ALBRES, R.S. \& LOPES, J.R.S. Disseminação de molicutes do milho a longas distâncias por Dalbulus maidis (Hemiptera: Cicadellidae). Fitopatologia Brasileira 27:091-095. 2002.

\section{RESUMO}

O objetivo do trabalho foi testar a hipótese de que a cigarrinha Dalbulus maidis (Hemiptera: Cicadellidae) serve como reservatório natural dos molicutes (Spiroplasma kunkelii e fitoplasma) que infetam o milho (Zea mays) no Mato Grosso do Sul, após períodos prolongados de pousio. Nas safras 1997/ 98 e 1998/99, avaliou-se a infetividade natural de migrantes desse inseto vetor em plantios de primavera (novembro/ dezembro) da região de Anastácio (MS), onde não se cultiva o milho na entressafra (abril a setembro), em duas situações distintas: (A) áreas onde o milho era plantado anualmente a partir de outubro, e (B) áreas onde o milho não era cultivado há vários anos. Cigarrinhas foram coletadas no campo e confinadas em plântulas sadias de milho, em casa de vegetação, para a inoculação dos patógenos. Após 50-60 dias, as plantas-teste foram avaliadas quanto a sintomas diagnósticos de $S$. kunkelii e por PCR para detecção de fitoplasma. Através dos bionsaios de transmissão, detectou-se S. kunkelii e fitoplasma em 2 a $20 \%$ e 1 a $4 \%$ dos indivíduos coletados, respectivamente. O aparecimento de adultos infetivos logo após a germinação da cultura, inclusive nas áreas onde o milho não era cultivado há vários anos, sugere que os molicutes foram transportados na entressafra por indivíduos migratórios de $D$. maidis.

Palavras-chave adicionais: enfezamento pálido, enfezamento vermelho, cigarrinha-do-milho, ecologia.

\section{ABSTRACT \\ Long-distance spread of maize mollicutes by Dalbulus maidis (Hemiptera: Cicadellidae)}

This study was designed to test the hypothesis that Dalbulus maidis (Hemiptera: Cicadellidae) serves as a natural source of mollicutes (Spiroplasma kunkelii and phytoplasma) that infect maize (Zea mays) following overseason in the State of Mato Grosso do Sul (MS), Brazil. The natural infectivity of $D$. maidis migrants was evaluated in spring plantings of 1997 and 1998 in the region of Anastácio (MS), where maize is not cultivated from April to September. Live leafhoppers were sampled in areas where: (A) maize was planted annually in the spring (October/December), and (B) maize had not been cultivated for several years. In a greenhouse, the leafhoppers were confined to healthy maize seedlings for pathogen inoculation. Two months later, the test plants were rated for diagnostic symptoms of $S$. kunkelii and tested by PCR for phytoplasma infection. Based on the transmission bioassays, $S$. kunkelii and phytoplasma were detected in 2 to $20 \%$ and 1 to $4 \%$ of the collected individuals, respectively. The appearance of infective adults soon after maize germination, even in the areas where maize had not been cultivated for several years, suggests that the mollicutes were transported in the overseason by migratory individuals of $D$. maidis.
A cigarrinha-do-milho, Dalbulus maidis (DeLong \& Wolcott) (Hemiptera: Cicadellidae), é considerada uma das pragas mais importantes em milho (Zea mays L.) na América Latina, principalmente pela sua capacidade de transmitir, de forma propagativa, o vírus da risca do milho (Maize rayado fino virus, MRFV) e os molicutes associados ao enfezamento do milho, Spiroplasma kunkelii Whitcomb et al. ("corn stunt spiroplasma", CSS) e fitoplasma ("maize bushy stunt phytoplasma”, MBSP) (Nault, 1980; 1990). Esses patógenos

\footnotetext{
"Parte da Tese de Doutorado do primeiro autor. Escola Superior de Agricultura "Luiz de Queiroz" (2000).

${ }^{* *}$ Bolsista da CAPES
}

podem causar perdas de até $100 \%$ da produção na cultura do milho, dependendo da época da infecção e do híbrido utilizado (Nault, 1990). No Brasil, a incidência de doenças do milho associadas aos molicutes aumentou consideravelmente nos últimos anos, principalmente nas regiões Sudeste e CentroOeste (Oliveira et al., 1998).

Estudos da atividade de vôo e comportamento de fuga de $D$. maidis têm indicado um alto potencial de migração e dispersão para esta espécie (Heady \& Nault, 1985; Taylor et al., 1993). É capaz de se deslocar por longas distâncias, como sugere o surto de CSS na Flórida, em 1979, provavelmente resultado da migração de cigarrinhas vindas de ilhas do Caribe (Bradfute et al., 1981). A capacidade de migração parece ser 
especialmente importante para insetos que, como a cigarrinhado-milho, utilizam apenas milho e teosintos (Zea spp.) como hospedeiro para sua reprodução e desenvolvimento (Nault, 1990). Milho e alguns teosintos são também os únicos hospedeiros naturais relatados para S. kunkelii e MBSP (Nault, 1980). Assim, postula-se que esses molicutes sobrevivam no vetor em áreas e épocas em que o milho não é cultivado, podendo ser disseminados a longas distâncias nessas circunstâncias.

Para investigar a hipótese de sobrevivência e transporte dos molicutes (S. kunkelii e fitoplasma do milho) em $D$. maidis durante a entressafra do milho, avaliou-se a infetividade natural de indivíduos migrantes dessa espécie de cigarrinha em plantios de primavera (outubro a dezembro) em região onde se cultiva pouco milho, com predominância de pastagens e entressafra prolongada (cerca de seis meses).

\section{Características das áreas experimentais e coleta de cigarrinhas}

O estudo foi realizado nas safras 1997/98 e 1998/99 no município de Anastácio (MS) (20²9' 01" S, 55 48' 25" W e $160 \mathrm{~m}$ de altitude), onde não se cultiva o milho no outono/ inverno (abril a setembro), em duas situações distintas: (A) áreas I e II: pequenas propriedades $(\approx 20$ ha) de subsistência, onde o milho era plantado anualmente a partir de outubro, seguido da cultura de feijão (Phaseolus vulgaris L.); e (B) áreas III, IV e V: propriedades ( $\approx 70 \mathrm{ha}$ ) cobertas por pastagens perenes, onde o milho não era cultivado há pelo menos cinco anos. As áreas de pastagens (II, IV e V) distavam pelo menos $20 \mathrm{~km}$ de áreas com plantio anual de milho (inclusive das áreas I e II). O município do estudo localiza-se na região oeste do Estado do Mato Grosso do Sul, cuja principal atividade agrícola consiste na pecuária e fruticultura, estando afastado de grandes áreas produtoras de milho por uma distância superior a $50 \mathrm{~km}$.

Nos meses de novembro e dezembro de cada safra, o solo foi preparado e adubado (NPK 4:14:8), e plantou-se em todas as áreas a variedade de milho BR-106 em talhões de aproximadamente $2.000 \mathrm{~m}^{2}$, com exceção da área $\mathrm{V}$, que só foi avaliada na safra 1998/99.

Utilizando-se aspirador bucal, foram coletadas amostras de mais de 50 adultos de D. maidis diretamente das plantas de milho, em cada uma das áreas, em diferentes fases da cultura. Na safra 1997/98 coletaram-se cigarrinhas logo após a emergência da cultura $(<30$ dias $)$ nas áreas III e IV, no meio da safra (60-90 dias) na área II e no final da safra (>90 dias) nas áreas I e IV. As coletadas na safra 1998/ 99 foram realizadas logo após a emergência da cultura nas áreas I, IV e V, no meio da safra nas áreas II e IV e no final da safra na área I. Em todas as coletas os espécimes foram colocados em caixas plásticas contendo uma camada de gesso umedecido no fundo e pedaços de folhas de milho. Este procedimento permitiu o transporte de espécimes vivos até o laboratório em Piracicaba (SP), onde se procedeu a análise de infetividade natural pelos molicutes através de bioensaios de transmissão.

\section{Bioensaios de transmissão}

Os insetos coletados foram confinados sobre plantasteste em gaiolas teladas, em grupos de quatro a sete indivíduos por planta, durante um período de acesso à inoculação (PAI) de quatro dias. Como plantas-teste foram usadas plântulas sadias de milho híbrido XL 330, no estádio de três a quatro folhas, obtidas em potes plásticos de $10 \mathrm{~cm}$ de diâmetro. Após o PAI, as plantas-teste foram transplantadas individualmente para potes plásticos maiores (22 $\mathrm{cm}$ de diâmetro), sendo mantidas em casa de vegetação livre de cigarrinhas para desenvolvimento de sintomas. Grupos de três a cinco plantasteste não inoculadas foram usadas como controle negativo em cada bioensaio de transmissão. As plantas foram pulverizadas com inseticida (mevinfós, $2,5 \mathrm{ml} / 1$ de calda) para se eliminarem ninfas de $D$. maidis que eventualmente eclodissem. Estas plantas foram fertilizadas periodicamente com nitrocálcio. Semanalmente as plantas-teste foram avaliadas quanto à presença de sintomas diagnósticos de $S$. kunkelii (estrias cloróticas no limbo foliar) (Nault, 1980). A presença do espiroplasma em plantas com estrias cloróticas foi confirmada pelo teste PTA-ELISA ("plate-trapped antigen enzyme-linked immunosorbant assay") (Mowat \& Dawson, 1987) com anti-soro policlonal para S. kunkelii, utilizandose a fosfatase alcalina como enzima e o fosfato de nitro-fenil como substrato. $\mathrm{O}$ anti-soro foi gentilmente cedido pelo Dr. Donald Gordon (Ohio State University, Wooster, OH, USA).

Para detectar infecções por fitoplasma, amostras de folhas das plantas-teste com sintomas de enfezamento ou descoloração de folhas (com ou sem estrias cloróticas) foram coletadas após 50-60 dias do PAI, e submetidas ao teste de PCR ("Polimerase Chain Reaction"). A extração e amplificação de DNA das amostras foram conduzidas conforme descrito por Lee et al. (1995), utilizando-se os oligonucleotídeos R16F2N (5'-ACG ACT GCT AAG ACT GG-3') e R16R2 (5'-TGA CGG GCG GTG TGT ACA AAC CCC G-3), que possibilitam amplificar o gene 16S do rDNA de fitoplasmas.

Pelo fato de os espécimes terem sido testados em grupos sobre as plantas-teste, a taxa individual de infetividade das cigarrinhas para os dois molicutes foi estimada com base na fórmula proposta por Swallow (1985), $\mathrm{I}=1-(1-p)^{1 / k}$, sendo $p$ a proporção de plantas infetadas no bioensaio de transmissão e $k$ o número de cigarrinhas confinadas por planta-teste.

Adultos de D. maidis foram observados e coletados em milho em todos os talhões experimentais, inclusive nas áreas III, IV e V onde não se cultivava milho. Foram realizados 11 bioensaios de transmissão com um total de 797 cigarrinhas coletadas e 158 plantas-teste avaliadas (Tabela 1). Estrias cloróticas diagnósticas de S. kunkelii (Nault, 1980) puderam ser observadas em 39 (97,5\%) de um total de 40 plantas com sintomas de enfezamento nos bioensaios de transmissão, aos 50-60 dias após o PAI. A análise por PCR das 40 plantas sintomáticas (enfezamentos pálido ou vermelho), revelou que apenas cinco $(12,5 \%)$ estavam infetadas com fitoplasma, sendo que $4(10 \%)$ apresentaram infecção pelos dois molicutes. 
A porcentagem de cigarrinhas infetivas (S. kunkelii e/ ou fitoplasma) nas diferentes áreas avaliadas e nas duas safras variou de 1 a 20\% (Tabela 1). Na safra 1997/98, a porcentagem de cigarrinhas infetivas com $S$. kunkelii variou de 2 a $16 \%$, não se detectando nenhum espécime infetivo com fitoplasma. Na safra 1998/99, a porcentagem de espécimes de D. maidis infetivos com espiroplasma ficou entre 3 a $20 \%$; para fitoplasma esta porcentagem variou de 1 a $4 \%$. As freqüências de espécimes positivos para $S$. kunkelii foram maiores do que para fitoplasma em todas as áreas.

As cigarrinhas migrantes, coletadas logo após a germinação do milho (<30 dias) na safra 1997/98, mostraram taxas de infetividade por S. kunkelii de 6 e $2 \%$ nas áreas III e IV, respectivamente (Tabela 1). Na safra 1998/99, as taxas de infetividade por S. kunkelii e por fitoplasma em cigarrinhas migrantes foram de 20 e 8\% (área IV) e 4 e 1\% (área V), respectivamente. Essas áreas (III, IV e V) eram constituídas de pastagens perenes onde o milho não havia sido cultivado há pelo menos cinco anos. A área IV, que anteriormente era pastagem, apresentou um aumento na freqüência de espécimes positivos na safra 1998/99, possivelmente pelo fato de que nessa área o milho passou a ser plantado de forma escalonada a partir de 1997/98, aumentando, assim, a quantidade de inóculo. A área I (safra 1998/99), onde o milho era plantado anualmente, apresentou indivíduos de D. maidis infetivos por S. kunkelii e por fitoplasma em taxas de 3 e $2 \%$, respectivamente, na amostragem com menos de 30 dias. As cigarrinhas coletadas no meio da safra (60-90 dias) mostraram taxas de infetividade por S. kunkelii de 2\% na área II, na safra 1997/ 98, e de $10 \%$ nas áreas II e IV, na safra 1998/99. A porcentagem de indivíduos infetivos por S. kunkelii no final de safra (>90 dias) atingiu 16\% na área I, em 1997/98. Cigarrinhas infetivas coletadas no meio e no final de safra podem ter adquirido os molicutes de plantas com enfezamentos dentro do próprio plantio (disseminação secundária), uma vez que este inseto pode produzir no mínimo duas gerações durante o ciclo da cultura (Todd et al., 1991) e os sintomas das doenças, dependendo da temperatura, podem ser observados a partir de duas semanas da inoculação (Nault, 1980). Após a aquisição pelas cigarrinhas de uma planta infetada, os molicutes têm um período de latência no vetor que varia de 17 a 23 dias para $S$. kunkelii, e de 22 a 28 dias para MBSP, a $27 \pm 2{ }^{\circ} \mathrm{C}$ (Nault, 1980). Devido aos períodos relativamente longos de incubação na planta e de latência no vetor de $S$. kunkelii e do fitoplasma, é pouco provável que as cigarrinhas infetivas coletadas no início da cultura (<30 dias) tenham adquirido os molicutes de plantas doentes do próprio talhão experimental.

Estudos conduzidos nas Américas do Norte e Central indicaram que tanto $D$. maidis como os molicutes $S$. kunkelii e fitoplasma apresentam uma gama restrita de plantas hospedeiras naturais para reprodução, constituída basicamente de milho e teosintos (Nault, 1980; Larsen et al., 1992), embora já tenha sido relatada a criação de D. maidis em Tripsacum dactyloides L. (Pitre et al., 1966), bem como a transmissão experimental de $S$. kunkelii para algumas dicotiledôneas (Markham et al., 1977). Assim, pouco se sabe a respeito de como $D$. maidis e esses molicutes sobrevivem na entressafra do milho, em regiões onde teosintos não ocorrem ou são raros. Esta cigarrinha, que é abundante durante a cultura do milho, desaparece dos campos após a seca da folhagem. Nault (1990) e Larsen et al. (1992) sugerem como possíveis estratégias para esta espécie no México, a sobrevivência em plantios de milho irrigado ou em hábitats adjacentes aos campos de milho, ou a hibernação de adultos nos restos culturais ou vegetação próxima de plantios. Alternativamente, a migração e dispersão

TABELA 1 - Estimativas de infetividade natural por Spiroplasma kunkelii e fitoplasma em adultos de Dalbulus maidis amostrados na região de Anastácio (MS), em diferentes áreas e fases da cultura do milho, na safra 1997/98 e 1998/99

\begin{tabular}{|c|c|c|c|c|c|c|c|}
\hline & \multirow[t]{2}{*}{ Área } & \multirow{2}{*}{$\begin{array}{c}\text { Fase da cultura } \\
\text { (dias após } \\
\text { germinação) }\end{array}$} & \multirow{2}{*}{ 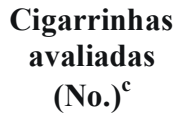 } & \multicolumn{2}{|c|}{$\begin{array}{l}\text { Proporção de plantas-teste } \\
\text { infetadas no bioensaio }\end{array}$} & \multicolumn{2}{|c|}{$\begin{array}{c}\text { Cigarrinhas } \\
\text { infetivas }(\%)^{d}\end{array}$} \\
\hline & & & & S. kunkelii & fitoplasma & S. kunkelii & fitoplasma \\
\hline \multirow{5}{*}{ 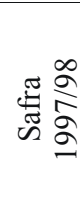 } & $\mathrm{I}^{\mathrm{a}}$ & $>90$ & 54 & $7 / 14$ & $0 / 14$ & 16 & 0 \\
\hline & II $^{\mathrm{a}}$ & $60-90$ & 65 & $1 / 16$ & $0 / 16$ & 2 & 0 \\
\hline & III $^{\mathrm{b}}$ & $<30$ & 72 & $4 / 14$ & $0 / 14$ & 6 & 0 \\
\hline & $\mathrm{IV}^{\mathrm{b}}$ & $<30$ & 110 & $2 / 15$ & $0 / 15$ & 2 & 0 \\
\hline & $\mathrm{IV}^{\mathrm{b}}$ & $>90$ & 90 & $0 / 18$ & $0 / 18$ & 0 & 0 \\
\hline \multirow{6}{*}{ 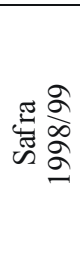 } & $\mathrm{I}^{\mathrm{a}}$ & $<30$ & 106 & $3 / 21$ & $2 / 21$ & 3 & 2 \\
\hline & $\mathrm{I}^{\mathrm{a}}$ & $>90$ & 50 & $0 / 10$ & $0 / 10$ & 0 & 0 \\
\hline & $\mathrm{II}^{\mathrm{a}}$ & $60-90$ & 50 & $4 / 10$ & $0 / 10$ & 10 & 0 \\
\hline & $\mathrm{IV}^{\mathrm{b}}$ & $<30$ & 60 & $8 / 12$ & $2 / 12$ & 20 & 4 \\
\hline & $I^{\mathrm{b}}$ & $60-90$ & 50 & $4 / 10$ & $0 / 10$ & 10 & 0 \\
\hline & $\mathrm{V}^{\mathrm{b}}$ & $<30$ & 90 & $6 / 18$ & $1 / 18$ & 8 & 1 \\
\hline
\end{tabular}

\footnotetext{
a Áreas onde o milho é plantado anualmente na primavera (outubro/novembro);

b Áreas de pastagens perenes onde não se cultivava milho há pelo menos 5 anos;

${ }^{\mathrm{c}}$ Espécimes foram avaliados em grupos de 4-7 por planta-teste, dependendo do bioensaio;

${ }^{\mathrm{d}}$ Estimativa da \% de espécimes infetivos baseando-se na fórmula de Swallow $(1985), \mathrm{I}=1-(1-p)^{1 / k}$, sendo $p$ a proporção de plantas infetadas no bioensaio de transmissão e $k$ o número de cigarrinhas confinadas por planta-teste.
} 
parecem ser estratégias importantes para a sobrevivência de insetos que utilizam hospedeiros de ciclo curto como o milho. Em países como o México e Guatemala, adultos de D. maidis podem ser encontrados em todas as espécies de teosintos amostradas, inclusive em plantas perenes do gênero Tripsacum (Nault, 1990). No entanto, somente depois que os campos de milho maturam e suas folhas secam é que as cigarrinhas procuram as folhas verdes de Tripsacum spp. No Brasil, as condições para sobrevivência da cigarrinha-do-milho na entressafra parecem ser mais drásticas, pelo menos com relação a hospedeiros alternativos, pois plantas como teosintos e Tripsacum são muito pouco comuns. Assim, na ausência de outras plantas hospedeiras, D. maidis estaria em completa dependência de seu hospedeiro primário, o milho, podendo utilizar a migração ou dispersão para a localização de novos cultivos ao final de cada safra.

A região de Anastácio (MS) tem como característica a presença de um extenso contínuo de pastagens perenes com cultivo do milho apenas em pequenas áreas de subsistência na primavera e verão (a partir de outubro), sendo que a entressafra estende-se por cerca de seis meses (abril a setembro). Áreas de cultivo intensivo de milho estão distantes mais de $50 \mathrm{~km}$. Especulamos, portanto, que as cigarrinhas que colonizaram os plantios em pastagens perenes (áreas III, IV e V) eram migrantes provenientes de locais distantes, uma vez que esses talhões experimentais distavam mais de $20 \mathrm{~km}$ de áreas de cultivo de subsistência e os plantios foram efetuados na mesma época. Esta hipótese vem sendo sustentada por estudos populacionais e genéticos de $D$. maidis conduzidos nas mesmas áreas por C. M. Oliveira (comunicação pessoal). Nesses estudos, nenhum espécime de $D$. maidis foi coletado nas áreas de pastagens perenes (III, IV e V) em vegetação adjacente aos talhões experimentais, especialmente gramíneas, com uso de rede de varredura, antes do plantio do milho. Esta hipótese de migração é congruente com estudos realizados por Taylor et al. (1993) que, avaliando a atividade de vôo de $D$. maidis em diferentes temperaturas de criação, luminosidade e condição de planta hospedeira, sugeriram um possível comportamento migratório para esta espécie. Estudos de comportamento de fuga de $D$. maidis em laboratório demonstraram a sua pronta aptidão para o vôo (Heady \& Nault, 1985), que é particularmente importante para espécies que utilizam hospedeiros sazonais, onde pequenos vôos poderiam levá-los para culturas próximas (Nault, 1990).

A coleta de cigarrinhas infetadas com $S$. kunkelii e fitoplasma nas áreas de pastagens perenes (III, IV e V), logo após a germinação do milho, sugere que os molicutes foram transportados na entressafra por espécimes migratórios de D. maidis, possivelmente oriundos de áreas distantes. Os dados também reforçam a hipótese de que $S$. kunkelii pode sobreviver no vetor, na ausência da planta hospedeira, durante períodos de entressafra (Ebbert \& Nault, 1994), especialmente por apresentar uma relação propagativa com o vetor. Madden et al. (1984) mostraram que $S$. kunkelii não é patogênico à cigarrinha-do-milho, não afetando a longevidade ou fecundidade de adultos em temperaturas entre 20 e $29^{\circ} \mathrm{C}$, enquanto que o
MBSP afetou significativamente estes parâmetros biológicos do vetor. Além disso, Ebbert \& Nault (1994) observaram que infecções por S. kunkelii propiciam alguns benefícios a $D$. maidis, como por exemplo, o aumento da sobrevivência, principalmente de fêmeas, em temperaturas entre 10 e $20^{\circ} \mathrm{C}$. Portanto, a maior freqüência de espécimes de $D$. maidis infetados por $S$. kunkelli do que por fitoplasma nas áreas estudadas pode estar associada à relação de mútuo benefício existente entre o espiroplasma e o vetor.

Os resultados deste estudo são relevantes para delinear estratégias de manejo visando minimizar os prejuízos causados por esses molicutes em milho na América Latina, uma vez que as primeiras cigarrinhas colonizando a cultura podem trazer consigo quantidades relativamente altas de inóculo, mesmo após meses de pousio. Para melhor compreender os mecanismos de sobrevivência e disseminação dos molicutes na entressafra do milho no Brasil, recomendam-se estudos mais abrangentes da gama de hospedeiros alternativos desses patógenos e do vetor, D. maidis.

\section{AGRADECIMENTOS}

Os autores agradecem aos Senhores Pedro Altiméia, José Dionísio, Aparecido, Eulício, Arlindo e Honório, pela permissão concedida à realização dos experimentos em suas propriedades em Anastácio (MS). Ao Eng. Agr. Milton Padovam, e em especial ao Tec. Agr. Célio Bernardes da Silveira, pelo valioso auxílio durante a execução do presente estudo. Ao Centro Universitário de Aquidauana (CEUA/ UFMS), em especial ao Prof. Dr. Manoel Araécio Uchoa Fernandes, pelo apoio logistíco e permissão de uso de suas instalações. À Coordenação de Aperfeiçoamento de Pessoal de Ensino Superior (CAPES) pela concessão da bolsa de estudo ao primeiro autor.

\section{REFERÊNCIAS BIBLIOGRÁFICAS}

BRADFUTE, O.E., TSAI, J.H. \& GORDON, D.T. Spiroplasma and viruses association with maize epidemic in southern Florida. Plant Disease 65:837-841. 1981.

EBBERT, A.M. \& NAULT, L.R. Improved overwintering ability in Dalbulus maidis (Homoptera: Cicadellidae) vector infected with Spiroplasma kunkelii (Mycoplasmatales: Spiroplasmatacea). Environmental Entomology 23:634-644. 1994.

HEADY, S.E. \& NAULT, L.R. Escape behavior of Dalbulus and Baldulus leafhoppers (Homoptera: Cicadellidae). Environmental Entomology 14:154-158. 1985.

LARSEN, K.J., NAULT, L.R. \& MOYA-RAYAGOSA, G. Overwintering biology of Dalbulus leafhoppers (Homoptera: Cicadellidae): adult population and drought hardiness. Environmental Entomology 21:566-577. 1992.

LEE, I.M., BERTACCINI, A., VIBIO, M. \& GUNDERSEN, D.E. Detection of multiple phytoplasmas in perennial fruit trees with decline symptoms in Italy. Phytopathology 85:728-735. 1995.

MADDEN, L.V., NAULT, L.R., HEADY, S.E. \& STYER, W.E. Effect of temperature on the population dynamics of three 
Dalbulus leafhoppers species. Annals of Applied Biology 108:475-485. 1984.

MARKHAM, P.G., TOWNSEND, R., PLASKITT, K. \& SAGLIO, P. Transmission of corn stunt to dicotyledonous plants. Plant Disease Reporter 61:342-345. 1977.

MOWAT, W.P. \& DAWSON, S. Detection of plant viruses by ELISA using crude sap extracts and unfractioned antisera. Journal of Virological Methods 15:233-247. 1987.

NAULT, L.R. Mayze bushy stunt and corn stunt: a comparison of disease symptoms, pathogens host ranges, and vectors. Phytophatology 70:659-662. 1980.

NAULT, L.R. Evolution of insect pest: maize and leafhopper, a case study. Maydica 35:165-175. 1990.

OLIVEIRA, E., WAQUIL, J.M., FERNANDES, F.T., PAIVA, E., RESENDE, R.O. \& KITAJIMA, E.W. "Enfezamento pálido" e "Enfezamento vermelho" na cultura do milho no Brasil
Central. Fitopatologia Brasileira 23:45-47. 1998.

PITRE, H.N., COMBS Jr., R.L. \& DOUGLAS W.A. Gammagrass, Tripsacum dactyloides: a new host of Dalbulus maidis, vector of corn stunt virus. Plant Disease Reporter 50:570571. 1966.

SWALLOW, W.H. Group testing for estimating infection rates and probabilities of disease transmission. Phytopathology 75:882889. 1985.

TAYLOR, R.A.J., NAULT, L.R. \& STYER, W.E. Experimental analysis of flight activity of three Dalbulus leafhoppers (Homoptera: Auchenorrhyncha) in relation to migration. Annals of the Entomological Society of America 86:655-667. 1993.

TODD, J.L., MADDEN, L.V. \& NAUT, L.R. Comparative growth and spatial distribution of Dalbulus leafhopper populations (Homoptera: Cicadellidae) in relation to maize phenology. Environmental Entomology 20:556-564. 1991. 